\title{
A Comparison of Vibration Magnitudes on the Tool with Different Subject According to the ISO 8662-7 Standard
}

\author{
Yoshichika SHIDA $^{1}$, Yoshiyuki NAKAGAWA ${ }^{1 *}$, Masaomi OKUNO ${ }^{1}$, \\ Setsuo MAEDA ${ }^{2}$ and Yoshiharu YONEKAWA ${ }^{2}$
}

\author{
${ }^{1}$ KUKEN Co., Ltd., 3-6-15 Nonoue, Habikino-city, Osaka 583-0871, Japan \\ ${ }^{2}$ National Institute of Industrial Health Ministry of Health, Labour and Welfare, 21-1, Nagao 6-chome, Tama-ku, \\ Kawasaki 214-8585, Japan
}

Received June 29, 2000 and accepted April 15, 2001

\begin{abstract}
Recently, ISO has defined the guidelines for the evaluation of the measurement and exposure limits of hand-transmitted vibrations at the handle of hand-held portable power tools. In a measurement of vibrations at pneumatic impact wrenches that tighten and remove screws. ISO 8862-7 standard: $1997^{1)}$ and ISO 5349 standard: $1986^{2}$ are set as international standards. In order to make an exact measurement of the quantities of vibrations exposed to the hand-arm system of a human body, ISO 8662-7 gives specifications to a measurement device and a loading device. As to a measurement device, for instance, the mass, installation method etc. of transducers and mechanical filters are defined. In addition, it specifies with each tolerance the working conditions of a pneumatic tool, the number of revolutions of socket in a loading device, the feed force, the number of subjects, and such an evaluation method as how to decide a declaration value of vibrations. These specifications give toolmakers a comparative measurement of vibration values of their tools before shipment. Meanwhile, although the measurement condition described in ISO8662-7: 1997 is that skilled operators conduct vibration measurement, no provisions as to operators are made in detail. Hence, this study focuses its concern on ambiguous work experience years in measuring vibrations of the tools in conformity with ISO 8662-7, and hereby the effect of years of work experience upon measurement values is considered and at the same time a knowledge of how to select operators is made clear.
\end{abstract}

Key words: Hand-transmitted vibration, Frequency-weighted r.m.s. acceleration, Pneumatic tool, Pneumatic impact wrenches, Skilled operators, Length-of-service

\section{Introduction}

The purpose of this study is to clarify issues in measuring vibrations of the tools by the method of the measurement and evaluation on the condition in adherence to ISO 8662 7. The vibrations of a hand-held power tool have serious effects upon the operator's health, whereas an operator of it must be on good health. In Europe, the EC Machinery Safety

*To whom correspondence should be addressed.
Directive, [89/392/EEC] $]^{3)}$ that came into effect in 1995 defines the target figure of the frequency-weighted r.m.s. acceleration as $2.5\left(\mathrm{~m} / \mathrm{s}^{2}\right)$ and smaller for the purpose of decreasing the vibrations of a hand-held power tool. Therefore, ISO at present makes the careful provisions for the measurement method and the subsequent evaluation method of vibrations of each hand-held power tool as to the measurement method of frequency-weighted r.m.s. acceleration at the handle of the tool. (ISO8662-1 14) ) $^{\text {) }}$ ISO 8662-7 provides the measurement and evaluation of 
Table 1. Excerpts from ISO8662-7: 1997

\begin{tabular}{|c|c|c|c|c|}
\hline \multicolumn{2}{|l|}{ Item } & \multicolumn{2}{|r|}{ Content } & Figure \\
\hline \multicolumn{2}{|c|}{ Measured quantities } & \multicolumn{2}{|c|}{$\begin{array}{l}\text { Frequency-weighted r.m.s. acceleration that is measured with a frequency weighting } \\
\text { filter for hand-arm vibration measurements, excerpted from ISO8662-1: } 1988\end{array}$} & \\
\hline \multirow[t]{5}{*}{ Measurement } & Transducer & Piezoelectric transducer etc. & The mass of a transducer and that of a mechanical & \\
\hline & Mechanical filter & $\begin{array}{l}\text { With the transducer in vibration } \\
\text { measurement of impact power } \\
\text { tools whose housing is made of } \\
\text { metals. }\end{array}$ & $\begin{array}{l}\text { filter must be smaller than } 5 \mathrm{~g} \text {, respectively. } \\
\text { NOTE ISO8662-1: } 1988 \text { provides that the total } \\
\text { mass of the vibration transducer and its } \\
\text { mounting, the mechanical filter, shall preferably } \\
\text { be less than } 50 \mathrm{~g} \text { and not more than } 5 \% \text { of the } \\
\text { mass of the tool complete with accessories. } \\
\text { On the other, ISO8662-7: } 1997 \text { describes as a } \\
\text { precaution that for light handles the mass of } \\
\text { transducer and its mounting shall be less than } 5 \mathrm{~g} \text {. }\end{array}$ & \\
\hline & $\begin{array}{l}\text { Measurement } \\
\text { direction and } \\
\text { measurement } \\
\text { location }\end{array}$ & \multicolumn{2}{|c|}{$\begin{array}{l}\text { The normal position of the transducer shall be halfway along the length of the handle } \\
\text { where the operator normally holds the hand-held power tool. } \\
\text { In the case of pistol control-handle power tools, the vibrations of the transducer } 1 \text { is } \\
\text { measured in the P-direction perpendicular to the operator's palm, and those of } \\
\text { transducer } 2 \text { in the same H-direction as the output shaft. }\end{array}$} & Figure 1 \\
\hline & Supply air pressure & \multicolumn{2}{|c|}{$0.63 \pm 0.015 \mathrm{MPa}(\mathrm{Pe}) ;$ this figure is quoted from ISO2787: $1984 .^{5)}$} & \\
\hline & Feed force & \multicolumn{2}{|c|}{$\begin{array}{l}\text { During testing, the operator press the hand-held portable power tool in a vertical } \\
\text { direction apply a feed force, a load equal to the } \pm 50 \% \text { weight of the tool body. } \\
\text { For example, if the mass of the body is } 1 \mathrm{~kg} \text {, the load becomes } 5 \text { to } 15 \mathrm{~N} \text {. }\end{array}$} & \\
\hline \multirow[t]{2}{*}{ Device } & Loading device & \multicolumn{2}{|c|}{$\begin{array}{l}\text { The loading device should be one specified in ISO } 8662-7: 1997 . \\
\text { The loading devise is installed on a concrete block whose mass is } 400 \mathrm{~kg} \text { and more } \\
\text { (See Fig. 2). }\end{array}$} & Figure 2 \\
\hline & Brake device & \multicolumn{2}{|c|}{$\begin{array}{l}\text { In the measurement, the brake of the loading device must be adjusted in order to obtain } \\
\text { a stable rotational frequency of the output shaft of }(0.15 \pm 0.05) \mathrm{s}^{-1} \text {, or } 9 \pm 3 \text { r.p.m. }\end{array}$} & \\
\hline Subjects & \multicolumn{3}{|c|}{$\begin{array}{l}\text { Three skilled operators shall each carry out one test series } 5 \text { times with the hand-held portable power tool } \\
\text { held and operated in a manner typical of normal use. } \\
\text { The time for each test shall not be less than } 4 \mathrm{~s} \text {. }\end{array}$} & \\
\hline $\begin{array}{l}\text { Validity of } \\
\text { test }\end{array}$ & \multicolumn{3}{|c|}{$\begin{array}{l}\text { The variation coefficient of five consecutive frequency-weighted r.m.s. acceleration, for the same operator, } \\
\text { is less than } 0.15 \text { or the standard deviation is less than } 0.30 \mathrm{~m} / \mathrm{s}^{2} \text {. } \\
\text { The coefficient of variation is: } \\
\qquad C_{V}=\frac{S_{n-1}}{\bar{x}} \\
\text { where the standard deviation is } \\
\qquad S_{n-1}=\sqrt{\frac{1}{n-1} \sum_{i=1}^{n}\left(x_{i}-\bar{x}\right)^{2}} \\
\text { and the mean value of the series is } \\
\qquad \bar{x}=\frac{1}{n} \sum_{i=1}^{n} x_{i} \\
\text { where } \\
x_{i} \text { is the ith value measured; } \\
n \text { is the number of measurement values. }\end{array}$} & \\
\hline $\begin{array}{l}\text { Declaration } \\
\text { value }\end{array}$ & \multicolumn{3}{|c|}{$\begin{array}{l}\text { The arithmetic mean of five values for each of the three operators, if their validity is checked, is calculated. } \\
\text { The arithmetic mean value in each direction is obtained as that of the three operators. } \\
\text { The largest of these overall arithmetic mean values is regarded as the declaration value. }\end{array}$} & \\
\hline
\end{tabular}




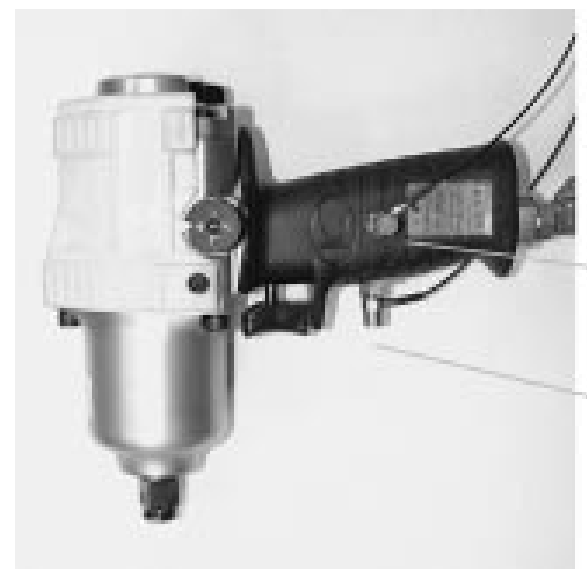

Transducer 1 in the P-direction

Transducer 2 in the $\mathrm{H}$-direction

Fig. 1. Measurement location and direction, according to ISO8662-7

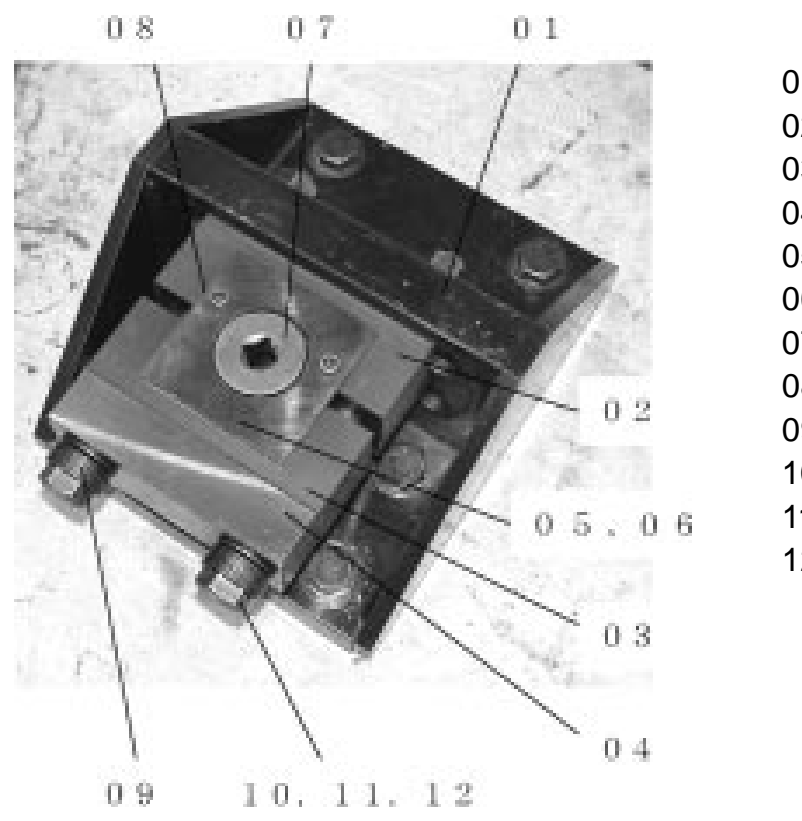

01 Base

02 Block, small

03 Block, small

04 Plate, small

05 Coverplate, small upper

06 Coverplate, small lower

07 Socket

08 Screw M6 $\times 60$

09 Cup spring

10 Screw M16 $\times 200$

11 Nut M16

12 Plain washer

Fig. 2. Loading device in the case of 1/2" Sq according to ISO8662-7

pneumatic impact wrenches, the subject of this study, where compressed air makes pneumatic motor revolve and the consequent impact clutches enable operators to tighten and remove screws. Table 1 shows the content of the provision. The measured quantities of vibrations are frequency-weighted r.m.s. acceleration prescribed in the EC Machinery Safety Directive, as shown in Table 1. In order to serve the purpose that the measurement can be made at any maker in any country, ISO 8662-7 gives specifications with each tolerance to a measurement device-including the mass of a transducer and a mechanical filter, installation method, measurement direction and location as shown in Fig. 1-the working conditions of a pneumatic tool, the number of revolutions of the socket in a loading device in Fig. 2, the feed force, the number of subjects, and such an evaluation method as how to decide the number of subjects and a declaration value of vibrations.

In this way, ISO8662-7: 1997 makes detailed specifications of the measurement method, but some obscure points can be found. One of them is deemed to be the description of subjects. ISO8662-7: 1997 describes just "skilled operators" as subjects but no concrete figure cannot be found. Therefore, this study checked the effect of the difference of operators upon measurement values, made clear the operator's factors 
influential in the measurement, and discussed the selection of the operators that will enable the measurement to be stable.

\section{Method}

\section{Subjects}

In this measurement, six "skilled operators" described in ISO8662-7: 1997 were selected. Table 2 exhibits the sex, age, length-of-service, height, and weight of each subject. Any of six persons was selected as an operator that was healthy and did not develop a hand-arm malfunction due to vibration. In the study, the skill of an operator is deemed to be parallel to length-of-serve in Table 2, and therefore their skills were eight to twenty years. The characteristics of these operators are considered to have satisfied the provisions of ISO8662-7 shown in Table 1. Hence, the data obtained from this study as to these operators is unlikely to make much difference with that from any other under the measurement condition in accordance with ISO8662-7.

\section{Characteristics of pneumatic impact wrenches operated in the experiment}

The pneumatic impact wrenches used in this experiment were ones that are sold in general and whose output-shaft sizes are 1/2"Sq and 3/4"Sq, and in the case of the same output-shaft size, both high-powered and low-powered models of wenches were selected. The output-shaft size in Fig. 3 is the width of the diagonal line of the square joint into which a socket is inserted and whose top is a hexagonalhead bolt. In this study, the six operators conducted the vibration measurements with four kinds of tools shown in Table 3. Then, while each of six subjects was operating the model A, B, C, and D of pneumatic impact wrenches, each frequency-weighted r.m.s. acceleration was measured.

\section{Measuring apparatus}

The vibrations of each pneumatic impact wrench were measured in line with the measurement system described in Fig. 4. In the measurement system, the signals from a vibrating transducer installed on the handle of a hand-held portable power tool are transmitted to a conditioning amplifier, and then the outputs are changed by an A/D converter after passing through an anti-areazing filter, and read by a computer. The frequency weighting of the digital data is made, based on the provisions of ISO5349, and thereby each frequency-weighted r.m.s. acceleration can be obtained. This system is what is called the HVLab Data Analysis System $^{6}$. Besides, the total weight of a transducer and a mechanical filter in Fig. 5 is $4.8 \mathrm{~g}$, according to the ISO8662-
Table 2. Subjects

\begin{tabular}{llcccc}
\hline No. & Sex & $\begin{array}{c}\text { Age } \\
\text { (year) }\end{array}$ & $\begin{array}{c}\text { Length-of- } \\
\text { service (year) }\end{array}$ & $\begin{array}{c}\text { Height } \\
(\mathrm{cm})\end{array}$ & $\begin{array}{c}\text { Body weight } \\
(\mathrm{kg})\end{array}$ \\
\hline 1 & female & 32 & 8 & 161 & 64.7 \\
2 & male & 40 & 19 & 168 & 61.5 \\
3 & male & 46 & 8 & 167 & 73.6 \\
4 & male & 42 & 20 & 164 & 62.5 \\
5 & male & 39 & 11 & 167 & 83.1 \\
6 & male & 41 & 18 & 170 & 90.3 \\
\hline \multicolumn{2}{l}{$\begin{array}{l}\text { Mean } \\
\text { Standard deviation }\end{array}$} & 40.0 & 14.0 & 166.0 & 72.6 \\
\hline
\end{tabular}
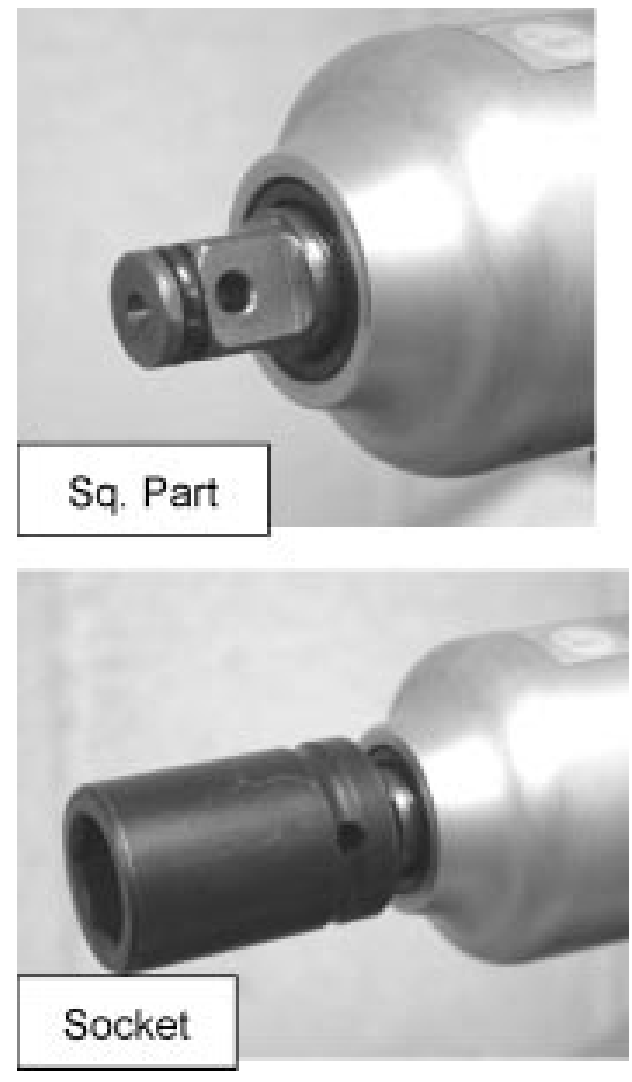

Fig. 3. Shape of output shaft

7 in Table 1. The conditioning amplifiers and the HVLab System adopted in this study was the ISO-compatible system developed by the Human Factors Research Unit, Institute of Sound \& Vibration Research in the University of Southampton (See Table 4).

\section{Experimental conditions and experimental procedure}

In the experiment, the loading device in Fig. 2 was installed on a concrete block of whose mass was $450 \mathrm{~kg}$, shown in 
Table 3. Pneumatic impact wrenches

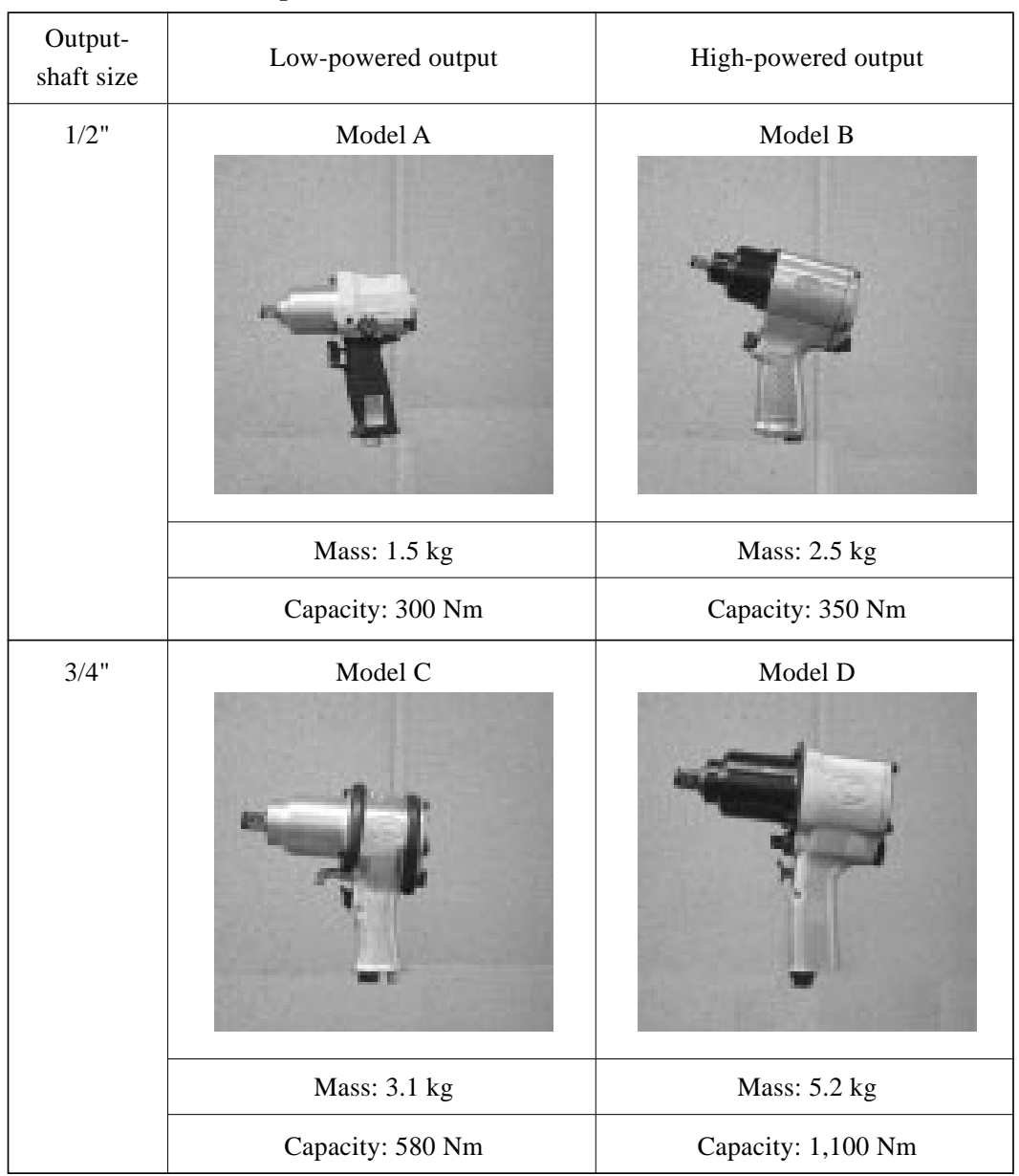

NOTE 1. Conditions in measuring the capacity are: Pneumatic pressure at non running: $0.63 \mathrm{MPa}(\mathrm{Pe})$

Used air hose: $6.5 \mathrm{~mm}$ caliber $\times 3 \mathrm{~m}$ long in the case of the output-shaft size of $1 / 2$ " Sq, and $12 \mathrm{~mm}$ caliber $\times 3 \mathrm{~m}$ long in the case of the output-shaft size of 3/4" Sq.

NOTE 2. Each actual object was photographically reduced to the same scale.
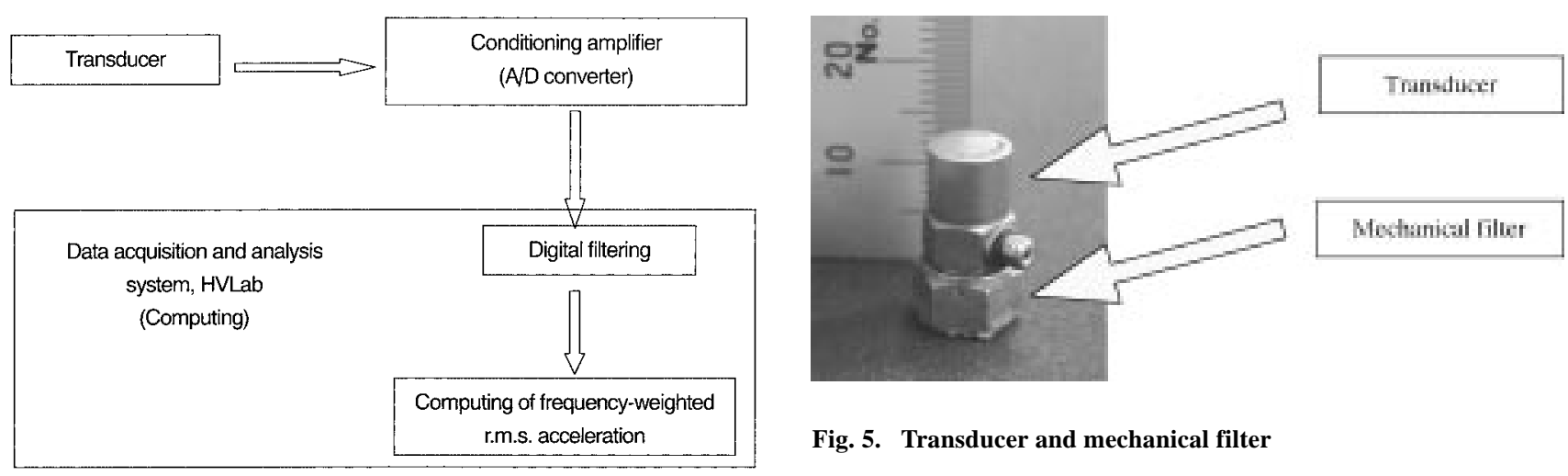

Fig. 5. Transducer and mechanical filter

Fig. 4. Block diagram of measuring apparatus 
Table 4. Measuring apparatus

\begin{tabular}{|c|c|c|c|c|c|}
\hline & \multicolumn{3}{|c|}{ Specification } & \multirow{2}{*}{$\begin{array}{c}\text { Accordance } \\
\text { with ISO }\end{array}$} & \multirow{2}{*}{ Figure } \\
\hline & Manufacturer & Type & Mass (g) & & \\
\hline Transducer & Brüel \& Kjær & \#4393 & 2.4 & $\bigcirc$ & \multirow[t]{2}{*}{ Figure 5} \\
\hline Mechanical filter & Brüel \& Kjær & WA-0224 & 2.4 & $\bigcirc$ & \\
\hline Conditioning amplifier & Brüel \& Kjær & \#2692 & & $\bigcirc$ & \\
\hline Data analysis system & \multicolumn{3}{|c|}{$\begin{array}{l}\text { HVLab System: this system was developed by } \\
\text { the Institute of Sound \& Vibration Research in } \\
\text { the University of Southampton. }\end{array}$} & $\bigcirc$ & \\
\hline
\end{tabular}

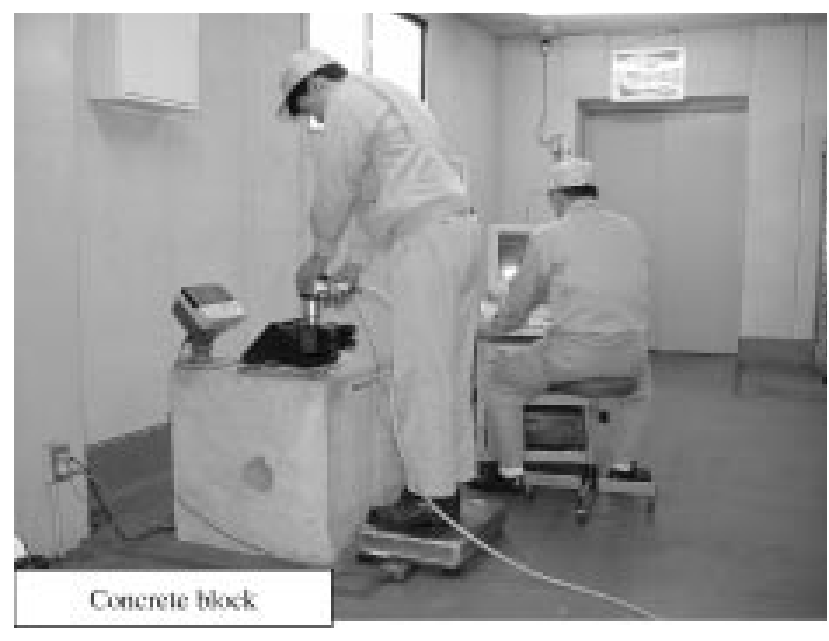

Fig. 6.a. Whole view of measuring apparatus

Fig. 6.a. Figure 6.b indicates how an operator kept the handle of a pneumatic impact wrench attached to a loading device in measuring vibrations of it. The loading brake of a loading device had the performance figures written in Table 5. In addition, the pneumatic air supplied with each of four kinds of tools was set to be $0.63 \mathrm{MPa}(\mathrm{Pe})$ in operating such tools, the sufficient air supply system was adopted that prevented the air pressure put in operating tools from being different among operators, and the air pressure by each operator was monitored for fear that it should change. Figure 7 shows measurement directions as to the vibrations of a pneumatic impact wrench attached to a loading device. Feed forces put on tools by each operator were able to be monitored through a digital scale set in front of a concrete block in Fig. 6.a. With these loading device and vibration measurement device, vibration measurements were performed on four kinds of hand-held power tools by each of six operators. In measuring vibrations, each operator was got to be posed as seen in Fig. 6, and to hold the tools in such ways as shown in Fig. 6.b. The figures of a feed

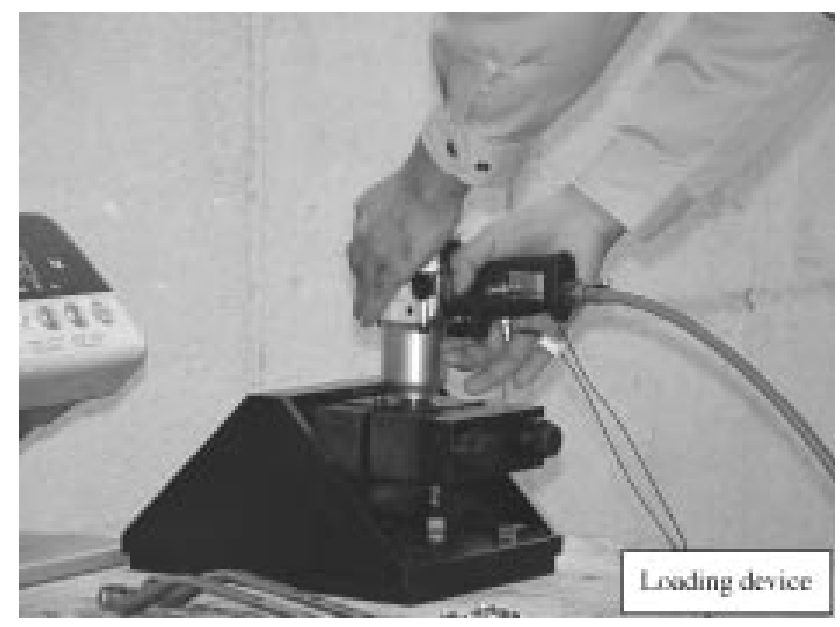

Fig. 6.b. Apparatus

force by each tool in Table 5 were designed to keep stable with monitoring them through the scale on the floor. Then, the tools were operated, the number of revolutions of the brake of the loading device was adjusted as provided in ISO8662-7. After this adjustment was completed, each subject started to give consecutive impacts on the loading device, and the stable vibrations after starting enabled the vibration measurement to be conducted for ten seconds. The turnaround time of this measurement was fifteen seconds from starting the impacts to finishing the measurement. The same measurement as this was repeated five times. In this procedure, the vibration measurement of each tool by each subject was conducted, and then each frequency-weighted r.m.s. acceleration was obtained.

\section{Results and Considerations}

Table 6 shows each frequency-weighted r.m.s. acceleration by each direction at five times when six operators operated the model A, B, C, and D of wrenches. 
Table 5. Experimental apparatus and method

\begin{tabular}{|c|c|c|c|c|}
\hline & & Setting & $\begin{array}{l}\text { Accordance } \\
\text { with ISO }\end{array}$ & Figure \\
\hline \multirow[t]{2}{*}{ Apparatus } & Loading device & Made as specified in ISO8662-7: 1997. & $\bigcirc$ & Figure 6 \\
\hline & Brake & $0.12 \sim 0.13\left(\mathrm{~s}^{-1}\right)$, or $7.5 \sim 8.6$ r.p.m. & $\bigcirc$ & \\
\hline \multirow[t]{8}{*}{ Measurement } & $\begin{array}{l}\text { Measurement direction } \\
\text { and location }\end{array}$ & $\begin{array}{l}\text { In P-direction and } \mathrm{H} \text {-direction } \\
\text { at the midst of the grip }\end{array}$ & $\bigcirc$ & Figure 7 \\
\hline & Supply air pressure & $0.63 \mathrm{MPa}(\mathrm{Pe})$ at non running & $\bigcirc$ & \\
\hline & Regulation on tools & maximum power dial & $\bigcirc$ & \\
\hline & \multirow[t]{4}{*}{ Feed Force } & Model-A & \multirow[t]{4}{*}{$\bigcirc$} & \\
\hline & & Model-B & & \\
\hline & & Model-C & & \\
\hline & & Model-D & & \\
\hline & Operation method & $\begin{array}{l}\text { Each subject gives consecutive impacts } \\
\text { on the loading device for } 10 \mathrm{~s} \text {. } \\
\text { This is repeated five times, and then, each } \\
\text { frequency-weighted r.m.s. acceleration is } \\
\text { measured. }\end{array}$ & $\bigcirc$ & \\
\hline
\end{tabular}

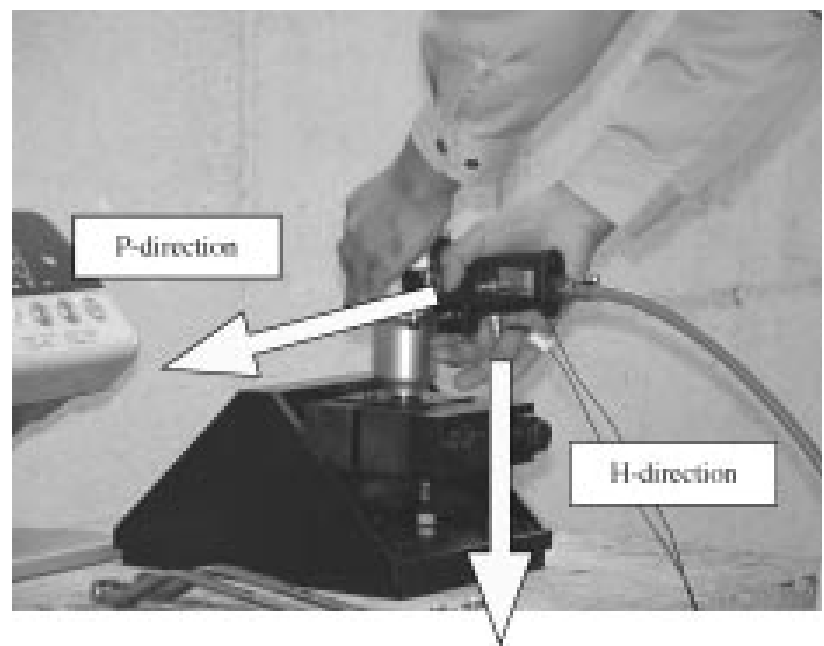

Fig. 7. Location and direction in measuring vibrations

Since each standard deviation or each variation coefficient in Table 6 falls under the validity of measurement values of ISO8662-7 in Table 1, each measured value of the individual operators meets the conditions specified in ISO.

The frequency-weighted r.m.s. acceleration averaged in one subject to another is exhibited by model and by direction in Table 7. Then, three mean values in the ascending numeric order were selected and marked by each of six subjects.

Besides, based on Table 7, Table 8 shows, by model, the maximum and minimum value of each frequency-weighted r.m.s. acceleration by subject, and difference between the two. Table 8 exhibits that the variation of each frequencyweighted r.m.s. acceleration between the model $\mathrm{A}$ and the model B was 1.24 to $1.29\left(\mathrm{~m} / \mathrm{s}^{2}\right)$ in the P-direction and 0.58 to $0.60\left(\mathrm{~m} / \mathrm{s}^{2}\right)$ in the H-direction, due to the difference of subjects, irrelevant to outputs. The same table shows that between the model C and the model D was 1.34 to $2.44(\mathrm{~m} /$ $\left.\mathrm{s}^{2}\right)$ in the P-direction and 0.66 to $1.97\left(\mathrm{~m} / \mathrm{s}^{2}\right)$ in the $\mathrm{H}$-direction.

The maximum variation of the frequency-weighted r.m.s. acceleration was $2.44\left(\mathrm{~m} / \mathrm{s}^{2}\right)$ though six "skilled operators" described in ISO8662-7: 1997 were selected and the vibration measurement was made.

According to the provisions in Table 1, the declaration value should be considered to be the largest of the overall arithmetic mean values using the mean value of five measurement values obtained for each of three operators. The data in Table 7 and Table 8, however, indicate that the variations of the measurement values will happen even though the measurement is made on the condition that subjects should be "skilled operators". With this being the situation, we discussed how to select "skilled operators" that meet the provision in ISO8662-7: 1997.

First, we reviewed the relationship between the frequencyweighted r.m.s. acceleration and the length-of-service of subjects by model, in order to study how the latter will have the influence upon the variations of the former. The relationships are shown in Fig. 8. The analysis of variance 
Table 6. Frequency-weighted r.m.s. acceleration by subject

\begin{tabular}{|c|c|c|c|c|c|c|c|c|c|c|}
\hline \multirow[t]{2}{*}{ Model } & \multirow[t]{2}{*}{ Subject } & \multirow[t]{2}{*}{ Direction } & \multicolumn{6}{|c|}{ Frequency-weighted r.m.s. accelerarion $\left(\mathrm{m} / \mathrm{s}^{2}\right)$} & \multirow{2}{*}{$\begin{array}{c}\text { Standard } \\
\text { deviation } \\
\mathrm{S}_{\mathrm{n}-1}<0.3\end{array}$} & \multirow{2}{*}{$\begin{array}{c}\text { Coefficient } \\
\text { of variation } \\
\mathrm{C}_{\mathrm{V}}<0.15\end{array}$} \\
\hline & & & $1 \mathrm{st}$ & 2nd & $3 \mathrm{rd}$ & 4th & 5 th & Mean value $x$ & & \\
\hline \multirow[t]{12}{*}{ A } & 1 & $\mathrm{P}$ & 2.87 & 2.91 & 2.96 & 2.97 & 2.99 & 2.94 & 0.05 & 0.02 \\
\hline & & $\mathrm{H}$ & 2.34 & 2.29 & 2.35 & 2.34 & 2.34 & 2.33 & 0.02 & 0.01 \\
\hline & 2 & $\mathrm{P}$ & 2.42 & 2.33 & 2.38 & 2.39 & 2.46 & 2.40 & 0.05 & 0.02 \\
\hline & & $\mathrm{H}$ & 2.43 & 2.42 & 2.45 & 2.17 & 2.00 & 2.29 & 0.20 & 0.09 \\
\hline & 3 & $\mathrm{P}$ & 3.01 & 3.01 & 2.98 & 2.89 & 2.65 & 2.91 & 0.15 & 0.05 \\
\hline & & $\mathrm{H}$ & 2.28 & 2.25 & 2.33 & 2.29 & 2.24 & 2.28 & 0.04 & 0.02 \\
\hline & 4 & $\mathrm{P}$ & 2.60 & 2.64 & 2.59 & 2.33 & 2.49 & 2.53 & 0.12 & 0.05 \\
\hline & & $\mathrm{H}$ & 2.49 & 2.70 & 2.36 & 2.53 & 2.69 & 2.55 & 0.14 & 0.06 \\
\hline & 5 & $\mathrm{P}$ & 1.61 & 1.65 & 1.64 & 1.73 & 1.62 & 1.65 & 0.05 & 0.03 \\
\hline & & $\mathrm{H}$ & 1.92 & 1.94 & 1.96 & 1.97 & 1.98 & 1.95 & 0.02 & 0.01 \\
\hline & 6 & $\mathrm{P}$ & 2.05 & 1.83 & 1.81 & 1.87 & 1.85 & 1.88 & 0.10 & 0.05 \\
\hline & & $\mathrm{H}$ & 1.91 & 1.98 & 2.09 & 1.96 & 1.92 & 1.97 & 0.07 & 0.04 \\
\hline \multirow[t]{12}{*}{ B } & 1 & $\mathrm{P}$ & 3.40 & 3.66 & 3.39 & 3.38 & 3.53 & 3.47 & 0.12 & 0.04 \\
\hline & & $\mathrm{H}$ & 2.92 & 2.70 & 2.87 & 2.54 & 2.37 & 2.68 & 0.23 & 0.09 \\
\hline & 2 & $\mathrm{P}$ & 2.78 & 2.85 & 2.74 & 2.87 & 2.92 & 2.83 & 0.07 & 0.03 \\
\hline & & $\mathrm{H}$ & 2.97 & 2.87 & 2.94 & 3.16 & 2.79 & 2.95 & 0.14 & 0.05 \\
\hline & 3 & $\mathrm{P}$ & 3.81 & 3.80 & 3.80 & 3.47 & 3.71 & 3.72 & 0.14 & 0.04 \\
\hline & & $\mathrm{H}$ & 3.47 & 2.87 & 3.27 & 3.01 & 3.01 & 3.13 & 0.24 & 0.08 \\
\hline & 4 & $\mathrm{P}$ & 3.50 & 3.50 & 3.82 & 3.72 & 3.55 & 3.62 & 0.14 & 0.04 \\
\hline & & $\mathrm{H}$ & 3.32 & 3.18 & 2.92 & 3.17 & 3.30 & 3.18 & 0.16 & 0.05 \\
\hline & 5 & $\mathrm{P}$ & 2.34 & 2.39 & 2.83 & 2.31 & 2.51 & 2.48 & 0.21 & 0.09 \\
\hline & & $\mathrm{H}$ & 2.64 & 2.71 & 2.74 & 2.90 & 3.05 & 2.81 & 0.17 & 0.06 \\
\hline & 6 & $\mathrm{P}$ & 2.72 & 2.84 & 2.85 & 2.85 & 2.91 & 2.83 & 0.07 & 0.02 \\
\hline & & $\mathrm{H}$ & 2.71 & 2.74 & 2.88 & 2.50 & 2.15 & 2.60 & 0.28 & 0.11 \\
\hline \multirow[t]{12}{*}{$\mathrm{C}$} & 1 & $\mathrm{P}$ & 2.66 & 2.78 & 2.78 & 2.78 & 2.80 & 2.76 & 0.06 & 0.02 \\
\hline & & $\mathrm{H}$ & 2.11 & 2.08 & 2.38 & 1.90 & 2.11 & 2.12 & 0.17 & 0.08 \\
\hline & 2 & $\mathrm{P}$ & 2.59 & 2.74 & 2.75 & 2.76 & 2.80 & 2.73 & 0.08 & 0.03 \\
\hline & & $\mathrm{H}$ & 2.24 & 2.28 & 2.19 & 2.19 & 2.15 & 2.21 & 0.05 & 0.02 \\
\hline & 3 & $\mathrm{P}$ & 3.11 & 3.14 & 3.17 & 3.18 & 3.19 & 3.16 & 0.03 & 0.01 \\
\hline & & $\mathrm{H}$ & 2.77 & 2.58 & 2.81 & 3.06 & 2.70 & 2.78 & 0.18 & 0.06 \\
\hline & 4 & $\mathrm{P}$ & 3.09 & 3.22 & 3.24 & 3.25 & 3.27 & 3.21 & 0.07 & 0.02 \\
\hline & & $\mathrm{H}$ & 3.00 & 2.70 & 2.62 & 2.76 & 2.73 & 2.76 & 0.14 & 0.05 \\
\hline & 5 & $\mathrm{P}$ & 2.20 & 1.78 & 1.76 & 1.80 & 1.83 & 1.87 & 0.18 & 0.10 \\
\hline & & $\mathrm{H}$ & 2.19 & 2.48 & 2.63 & 2.63 & 2.68 & 2.52 & 0.20 & 0.08 \\
\hline & 6 & $\mathrm{P}$ & 2.10 & 2.03 & 1.99 & 2.02 & 2.00 & 2.03 & 0.04 & 0.02 \\
\hline & & $\mathrm{H}$ & 2.41 & 2.49 & 2.52 & 2.57 & 2.62 & 2.52 & 0.08 & 0.03 \\
\hline \multirow[t]{12}{*}{$\mathrm{D}$} & 1 & $\mathrm{P}$ & 4.24 & 4.64 & 3.96 & 4.02 & 3.82 & 4.14 & 0.32 & 0.08 \\
\hline & & $\mathrm{H}$ & 3.62 & 3.91 & 4.15 & 4.16 & 4.27 & 4.02 & 0.26 & 0.06 \\
\hline & 2 & $\mathrm{P}$ & 5.49 & 5.10 & 5.28 & 5.49 & 5.53 & 5.38 & 0.18 & 0.03 \\
\hline & & $\mathrm{H}$ & 3.11 & 3.19 & 2.76 & 3.11 & 3.06 & 3.05 & 0.17 & 0.05 \\
\hline & 3 & $\mathrm{P}$ & 4.21 & 4.24 & 4.32 & 4.37 & 4.43 & 4.31 & 0.09 & 0.02 \\
\hline & & $\mathrm{H}$ & 2.62 & 2.55 & 2.75 & 2.34 & 2.72 & 2.60 & 0.16 & 0.06 \\
\hline & 4 & $\mathrm{P}$ & 5.03 & 4.59 & 5.03 & 4.90 & 4.97 & 4.90 & 0.18 & 0.04 \\
\hline & & $\mathrm{H}$ & 2.58 & 3.14 & 2.81 & 2.71 & 3.41 & 2.93 & 0.34 & 0.12 \\
\hline & 5 & $\mathrm{P}$ & 2.59 & 2.93 & 2.96 & 3.04 & 3.17 & 2.94 & 0.22 & 0.07 \\
\hline & & $\mathrm{H}$ & 1.86 & 2.34 & 2.20 & 2.13 & 1.88 & 2.08 & 0.21 & 0.10 \\
\hline & 6 & $\mathrm{P}$ & 3.63 & 3.99 & 4.00 & 4.00 & 4.00 & 3.92 & 0.16 & 0.04 \\
\hline & & $\mathrm{H}$ & 2.26 & 2.18 & 1.97 & 1.90 & 1.95 & 2.05 & 0.16 & 0.08 \\
\hline
\end{tabular}


Table 7. Mean value of frequency-weighted r.m.s. acceleration $\left(\mathrm{m} / \mathrm{s}^{2}\right)$ by subject

\begin{tabular}{|c|c|c|c|c|c|c|c|c|c|c|}
\hline \multirow{2}{*}{ Output shaft size } & \multirow{2}{*}{ model } & \multirow{2}{*}{ Direction } & \multicolumn{6}{|c|}{ Mean value of each subject } & \multicolumn{2}{|c|}{ All of subjects } \\
\hline & & & 1 & 2 & 3 & 4 & 5 & 6 & Overall mean value & Standard deviation \\
\hline \multirow[t]{4}{*}{$1 / 2 "$} & A & $\mathrm{P}$ & 2.94 & 2.40 & 2.91 & 2.53 & (1.65) & 1.88 & 2.39 & 0.53 \\
\hline & & $\mathrm{H}$ & 2.33 & 2.29 & 2.28 & 2.55 & (1.95) & (1.97) & 2.23 & 0.23 \\
\hline & B & $\mathrm{P}$ & 3.47 & 2.83 & 3.72 & 3.62 & 2.48 & 2.83 & 3.16 & 0.51 \\
\hline & & $\mathrm{H}$ & 2.68 & 2.95 & 3.13 & 3.18 & 2.81 & 2.60 & 2.89 & 0.24 \\
\hline \multirow[t]{4}{*}{$3 / 4 "$} & $\mathrm{C}$ & $\mathrm{P}$ & 2.76 & 2.73 & 3.16 & 3.21 & (1.87) & 2.03 & 2.63 & 0.56 \\
\hline & & $\mathrm{H}$ & 2.12 & 2.21 & 2.78 & 2.76 & 2.52 & 2.52 & 2.49 & 0.27 \\
\hline & $\mathrm{D}$ & $\mathrm{P}$ & (4.14) & 5.38 & 4.31 & 4.90 & 2.94 & 3.92 & 4.27 & 0.84 \\
\hline & & $\mathrm{H}$ & 4.02 & 3.05 & (2.60) & 2.93 & 2.08 & 2.05 & 2.79 & 0.73 \\
\hline
\end{tabular}

Table 8. Maximum and minimum value of each frequency-weighted r.m.s. acceleration, and difference of the two by measurement direction

\begin{tabular}{cccccc}
\hline \multirow{2}{*}{$\begin{array}{c}\text { Output } \\
\text { shaft size }\end{array}$} & Model & Direction & \multicolumn{3}{c}{ Frequency-weighted r.m.s. Acceleration $\left(\mathrm{m} / \mathrm{s}^{2}\right)$} \\
\cline { 4 - 6 } 1/2" & A & $\mathrm{P}$ & 2.94 & 1.65 & 1.29 \\
& & $\mathrm{H}$ & 2.55 & 1.95 & 0.60 \\
& $\mathrm{~B}$ & $\mathrm{P}$ & 3.72 & 2.48 & 1.24 \\
& & $\mathrm{H}$ & 3.18 & 2.60 & 0.58 \\
\hline $3 / 4 "$ & $\mathrm{C}$ & $\mathrm{P}$ & 3.21 & 1.87 & 1.34 \\
& & $\mathrm{H}$ & 2.78 & 2.12 & 0.66 \\
& $\mathrm{D}$ & $\mathrm{P}$ & 5.38 & 2.94 & 2.44 \\
& & $\mathrm{H}$ & 4.02 & 2.05 & 1.97 \\
\hline
\end{tabular}

\begin{tabular}{|c|c|c|}
\hline $\begin{array}{l}\text { o MODEL-A, P-direction } \\
\text { \& MODEL-B, H-direction } \\
\text { o MODEL-D, P-direction }\end{array}$ & $\begin{array}{l}\text { - MODEL-A, H-direction } \\
\text { a MODEL-C, P-direction } \\
\text { - MODEL-D, H-direction }\end{array}$ & $\begin{array}{l}\triangle \text { MODEL-B, P-direction } \\
\text { - MODEL-C, H-direction }\end{array}$ \\
\hline
\end{tabular}

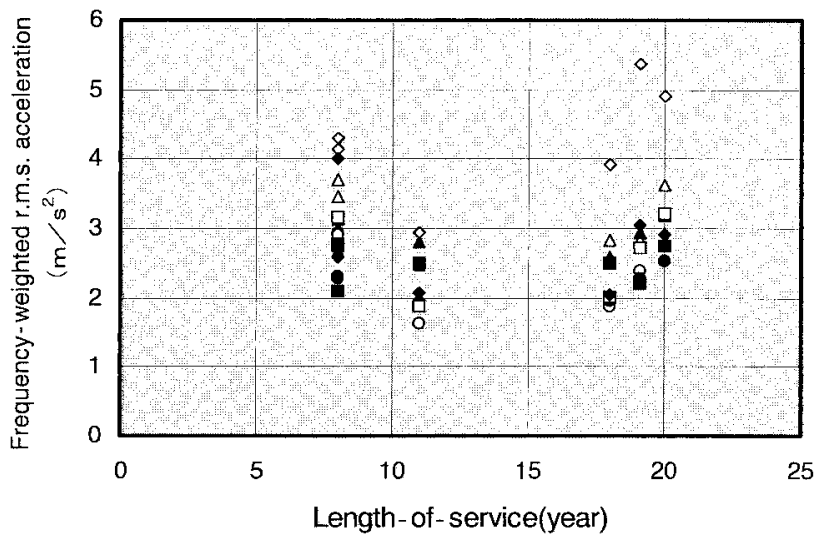

Fig. 8. Relationship between frequency-weighted r.m.s. acceleration and length-of-service of subjects by model A, B, C and D

was made of the data in Table 7 so as to investigate whether any influence of the length of service upon the frequencyweighted r.m.s. acceleration is found in the model A, B, C,
Table 9. Analysis of variance

\begin{tabular}{lcclc}
\hline \multicolumn{1}{c}{ Factors } & $\begin{array}{c}\text { Sum } \\
\text { squares }\end{array}$ & $\begin{array}{c}\text { Deg. } \\
\text { Freedom }\end{array}$ & $\begin{array}{c}\text { Mean } \\
\text { square }\end{array}$ & F. ratio \\
\hline A (Tools) & 10.442 & 3 & 3.4808 & $24.22^{* *}$ \\
B (Subjects) & 5.7181 & 5 & 1.1436 & $7.96^{* *}$ \\
C (Directions) & 3.1263 & 1 & 3.1263 & $21.76^{* *}$ \\
A*B & 2.4011 & 15 & 0.16007 & 1.11 \\
A*C & 3.7625 & 3 & 1.2542 & $8.73^{* *}$ \\
B C & 1.1537 & 5 & 0.23073 & 1.61 \\
Errors & 2.1555 & 15 & 0.1437 & \\
\hline Total & 28.76 & 47 & & \\
\hline
\end{tabular}

$* * \mathrm{p}<0.01$.

and D with regard to operators selected as "skilled operators" described in ISO8662-7: 1997. Table 9 shows the result.

Table 9 indicates that there were significant differences existed among operators. Therefore, this satisfies the validity of measurement values in ISO8662-7 shown in Table 1. Although data were taken from "skilled operators," the analysis of variance suggests that the measurement result varied depending on an operator. It follows from this result 
Table 10. Subject, added to Table 2

\begin{tabular}{|c|c|c|c|c|c|c|c|}
\hline No. & Sex & $\begin{array}{l}\text { Age } \\
\text { (year) }\end{array}$ & $\begin{array}{l}\text { Length-of- } \\
\text { service (year) }\end{array}$ & $\begin{array}{l}\text { Height } \\
(\mathrm{cm})\end{array}$ & $\begin{array}{c}\text { Body weight } \\
(\mathrm{kg})\end{array}$ & $\begin{array}{l}\text { Grip } \\
(\mathrm{N})\end{array}$ & $\begin{array}{l}\text { Weight of the } \\
\text { forearm }(\mathrm{kg})\end{array}$ \\
\hline 1 & Female & 32 & 8 & 161 & 64.7 & 320 & 1.10 \\
\hline 2 & Male & 40 & 19 & 168 & 61.5 & 400 & 1.09 \\
\hline 3 & Male & 46 & 8 & 167 & 73.6 & 430 & 1.17 \\
\hline 4 & Male & 42 & 20 & 164 & 62.5 & 520 & 1.15 \\
\hline 5 & Male & 39 & 11 & 167 & 83.1 & 610 & 1.60 \\
\hline 6 & Male & 41 & 18 & 170 & 90.3 & 600 & 1.63 \\
\hline \multicolumn{2}{|c|}{ Mean Value } & 40.0 & 14.0 & 166.0 & 72.6 & 480.0 & 1.29 \\
\hline \multicolumn{2}{|c|}{ Standard deviation } & 4.6 & 5.6 & 3.2 & 11.9 & 116.0 & 0.25 \\
\hline
\end{tabular}

that, even if the vibration measurement were conducted with "skilled operators" written in ISO8662-7, there would happen variations in data among operators. Heed should be paid to the clear fact that there arose some unevenness results among operators with length-of services of eight to twenty, adopted in this study. This means that differences of one measured data from another would occur even in conformity with the selection standard of operators of "skilled operators" specified in ISO8662-7.

In the results of analysis of variance summary table of the measured data as shown in Table 9, the main effects of the length of service were statistically significant $(\mathrm{p}<0.01)$. From Fig. 8, it is possible to divide the measured data into two groups according to the length of services of 8 to 11 years and 18 to 20 years.

The Mann-Whitney U test was used to test for differences between the length of services among all tools and all directions. There was no significant difference between two groups of the length of services. From the result of this test, it was clear that the length of services of the operators could not evaluate the differences of the measured data.

Subsequently, in order to exhibit what factors of subjects are likely to influence the variations of frequency-weighted r.m.s. acceleration, the impact of the physical characteristics of operators upon the frequency-weighted r.m.s. acceleration. Such characteristics are the weight of the right forearm of an operator, which he or she gripped the handle of a tool where a transducer was fixed, with his or her right hand, the body weight and the grip of an operator.

The weight of the forearm of an operator is calculated at the volume whose special gravity is presumed to be. The grip of an operator is measured by a hand dynamometer. The respective values are shown in Table 10.

Figure 9 shows the relationship between the weight of the forearm of each operator and the frequency-weighted r.m.s. acceleration as to the model A, B, C, and D. In the figures, the approximate lines are drawn so as to grasp the increasing or decreasing trends. From Fig. 9, it was discernible that the greater the weight of the forearm of an operator, the smaller the frequency-weighted r.m.s. acceleration may be likely to be in the model A, B, C, and D. In addition to this, Fig. 10 shows the nearly direct proportionality between the weight of the forearm of an operator and his or her body weight. Figure 11 indicates the relationship between each operator's body weight and frequency-weighted r.m.s. acceleration in the model A, B, $\mathrm{C}$, and D. It is inferred from the figure that the heavier the body weight of each operator, the smaller frequency-weighted r.m.s. acceleration is likely to be in the model A, B, C, and D.

As an additional plus, Fig. 12 exhibits the relationship between the grip of each operator and the frequency-weighted r.m.s. acceleration. It follows from the figure that the stronger the grip of each operator, the smaller frequency-weighted r.m.s. acceleration seems to be in the model A, B, C, and D.

To sum up, the experimental results is as follows. When the measurements were made with regard to operators who were selected as "skilled operators" described in ISO86627: 1997, and the variations of the frequency-weighted r.m.s. acceleration were recorded in the Model A, B, C, and D, the heavier the weight of each operator, the weight of the forearm of an operator, and his or her weight, the smaller frequency-weighted r.m.s. acceleration is likely to be. The stronger his or her grip, the smaller frequency-weighted r.m.s. acceleration is likely to be. However, since it is considered that there are some operators whose body weight is heavy but whose arms are slender, the value is deemed to be unable to be defined on the basis of only one of the characteristics of an operator.

Accordingly, Fig. 13 shows the relationship between the value and the operator's Body Mass Index (BMI) (See Table 11) which is internationally used in general. From Fig. 13, 

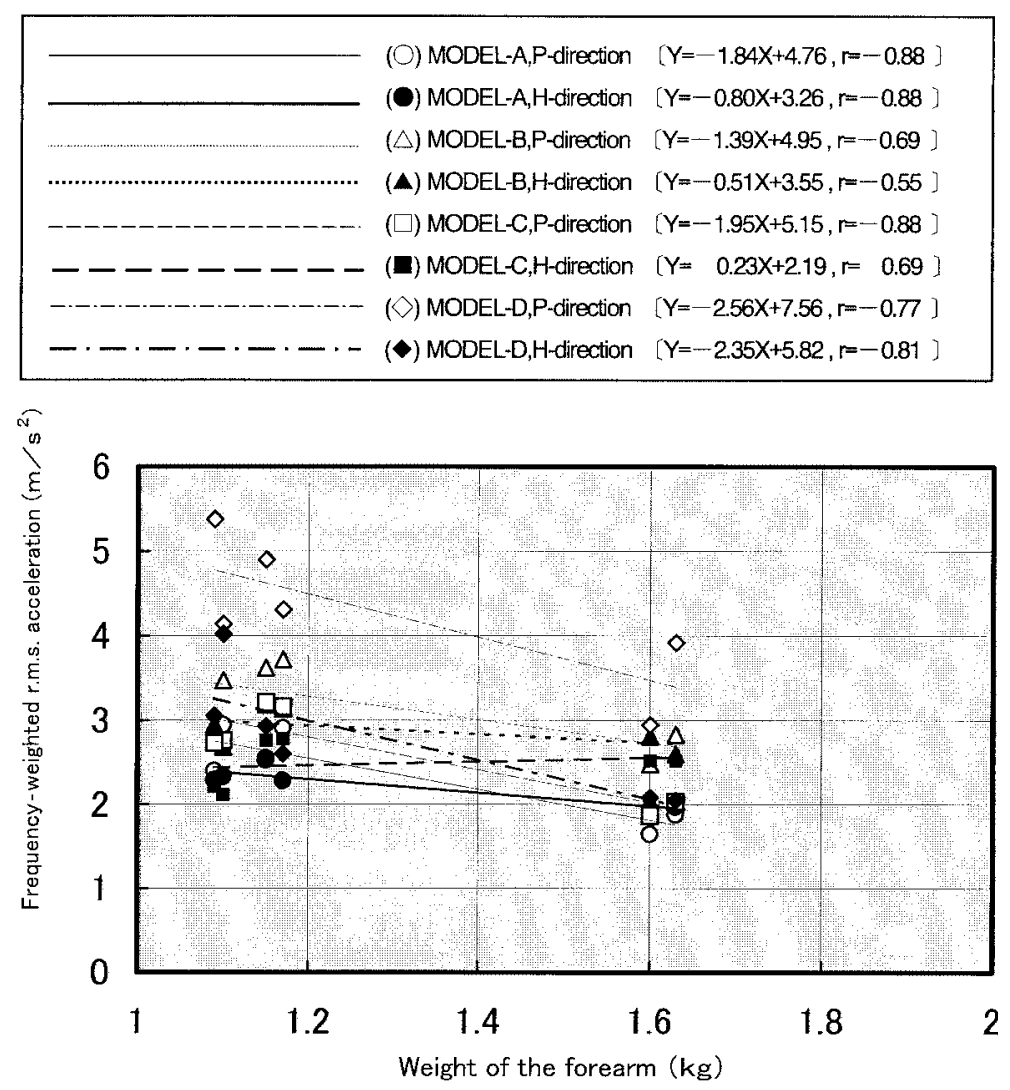

Fig. 9. Relationship between frequency-weighted r.m.s. acceleration and weight of the forearm of subjects by model A, B, C and D

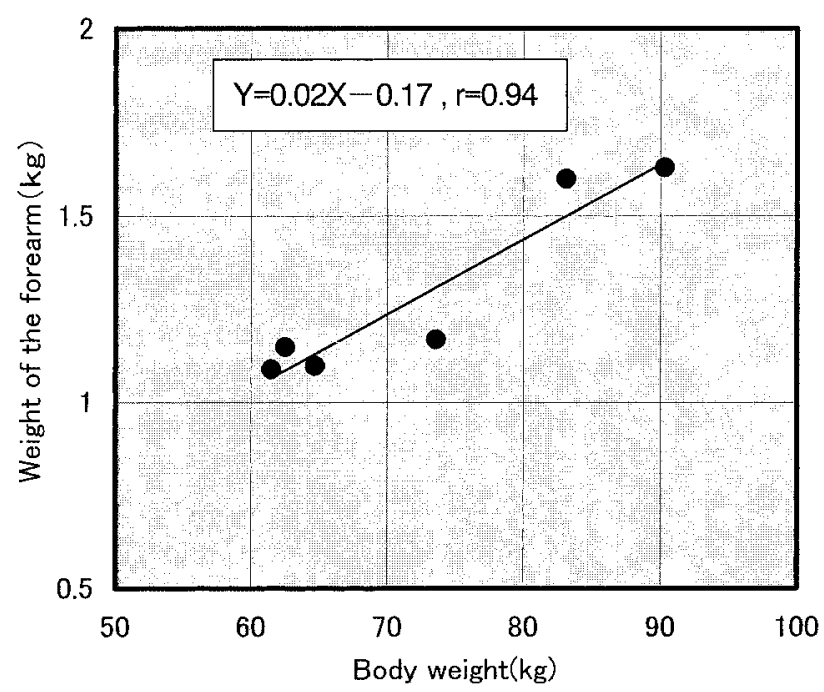

Fig. 10. Relationship between weight of the forearm and body weight of subjects it was discernible that the greater the BMI of each operator, the smaller the frequency-weighted r.m.s. acceleration may be likely to be in the model A, B, C, and D, except as to data in the case of the H-direction of the model C.

From Figures 9 and 13, it is possible to divide the measured data into two groups according to the weight of the right forearm of operators between 1.09 to $1.17 \mathrm{~kg}$ and 1.60 to $1.63 \mathrm{~kg}$ or BMI between 21.8 to 25.0 and 29.8 to 31.3. The Mann-Whitney $\mathrm{U}$ test was used to test for differences between the weight of the right forearm or BMI of the operators. There was significant difference between two groups of the weight of the right forearm or BMI of the operators.

From the result of this test, it was clear that the weight of the right forearm or BMI of the operators is depending on the differences of the measured data.

Although ISO8662-7 recommends the vibration measurement with "skilled operators", this study shows that, even though with skilled operators, any measurement with skilled operators would create different data due to their physical characteristics. This implies that any vibration measurement of tools would be brought into the same result 

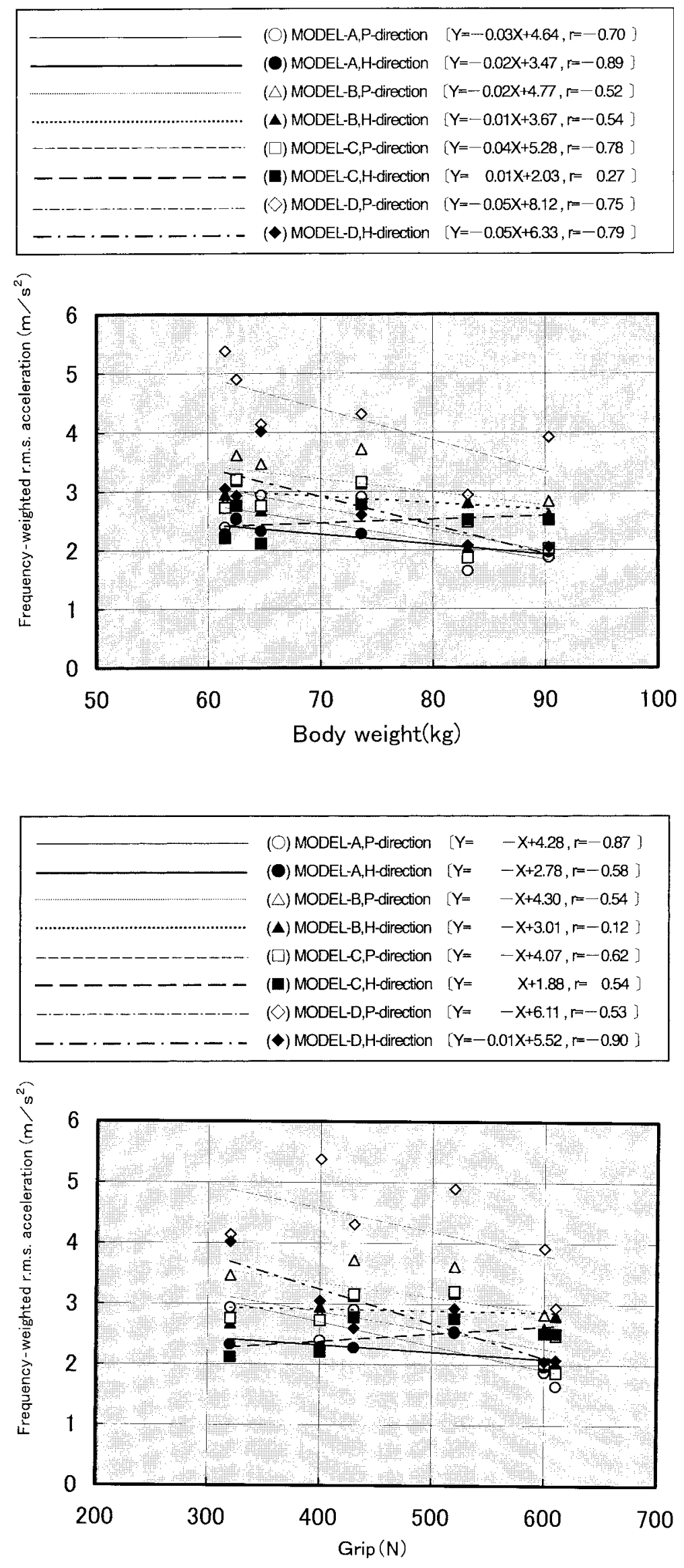

Fig. 11. Relationship between frequencyweighted r.m.s. acceleration and body weight of subjects by model A, B, C and D
Fig. 12. Relationship between frequencyweighted r.m.s. acceleration and grip of subjects by model A, B, C and D 

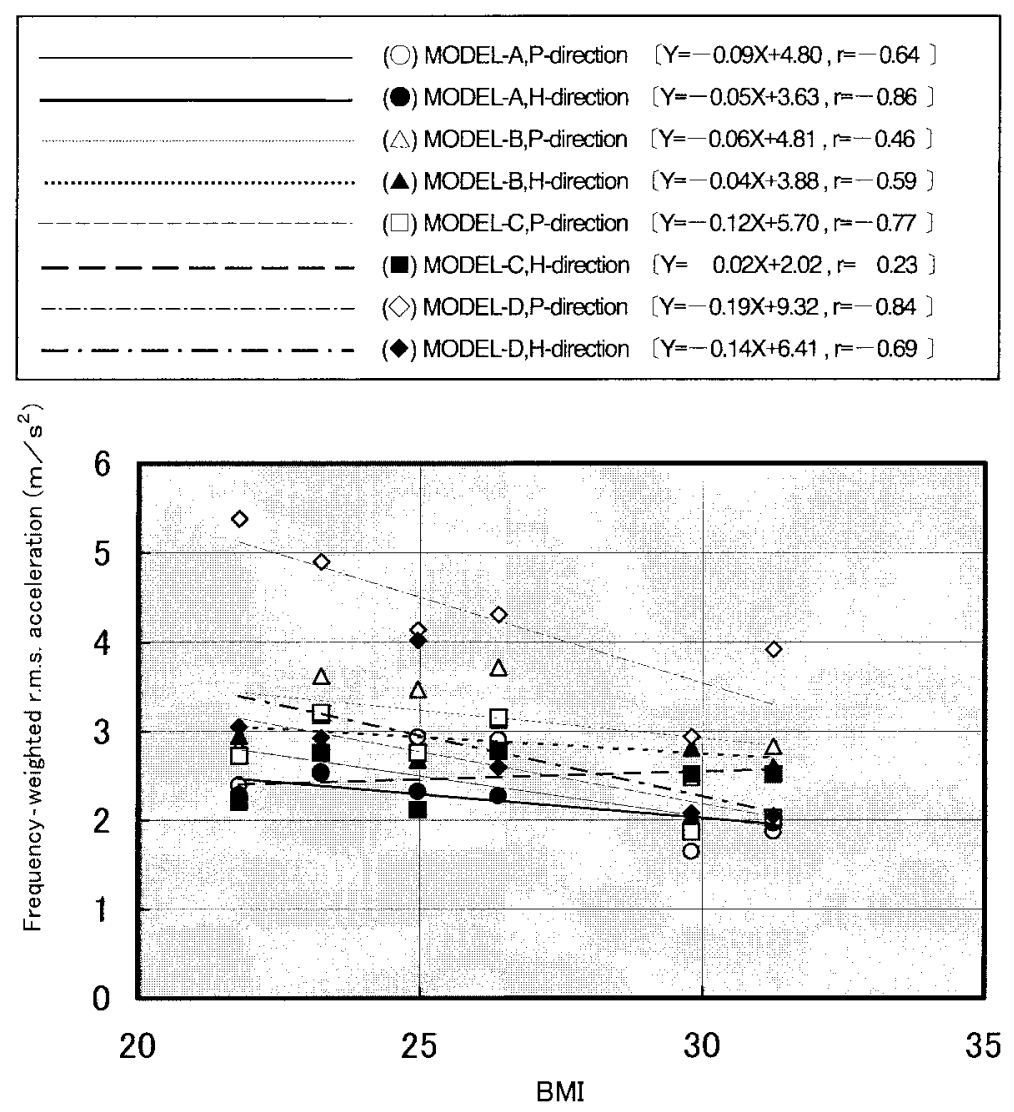

Fig. 13. Relationship between frequency-weighted r.m.s. acceleration and BMI of subjects in model A, B, C and D

Table 11. BMI of Subject, added to Table 2

\begin{tabular}{ccccccc}
\hline No. & Sex & $\begin{array}{c}\text { Age } \\
\text { (year) }\end{array}$ & $\begin{array}{c}\text { Length-of- } \\
\text { service (year) }\end{array}$ & $\begin{array}{c}\text { Height } \\
(\mathrm{cm})\end{array}$ & $\begin{array}{c}\text { Body weight } \\
(\mathrm{kg})\end{array}$ & BMI* $^{*}$ \\
\hline 1 & Female & 32 & 8 & 161 & 64.7 & 25.0 \\
2 & Male & 40 & 19 & 168 & 61.5 & 21.8 \\
3 & Male & 46 & 8 & 167 & 73.6 & 26.4 \\
4 & Male & 42 & 20 & 164 & 62.5 & 23.2 \\
5 & Male & 39 & 11 & 167 & 83.1 & 29.8 \\
6 & Male & 41 & 18 & 170 & 90.3 & 31.3 \\
\hline \multicolumn{2}{l}{ Mean Value } & 40.0 & 14.0 & 166.0 & 72.6 & 26.2 \\
\multicolumn{2}{l}{ Standard deviation } & 4.6 & 5.6 & 3.2 & 11.9 & 3.70 \\
\hline
\end{tabular}

*NOTE: BMI = Body weight $(\mathrm{kg}) /\{\text { Height }(\mathrm{m})\}^{2}$.

if it were conducted with operators. Hence, it seems necessary that ISO8662-7 should include the provision that the vibration measurement shall be conducted with skilled operators whose physical characteristics or BMI are concretely defined, not with ambiguous "skilled operators".

\section{Conclusions}

This study was conducted in accordance with ISO86627: 1997 and ISO5349: 1986. The description of operators, however, is ambiguous, and to make clear the influence of such ambiguity upon measurement values, we selected six "skilled operators" as the subjects and the vibration 
measurement was made with the representative model A, B, C, and D of pneumatic impact wrenches. Subsequently, the investigation was made on the relationships among the skill of operators, their physical characteristics, and frequency-weighted r.m.s. acceleration.

The results of this study are:

1) The vibration measurement data on each operator satisfied the validity of test in ISO8662-7, it is evident that the difference of the skill or length-of-service of each operator caused that of each frequency-weighted r.m.s. acceleration measured.

2) It is discernible that the greater the weight of the forearm of an operator, the smaller the frequency-weighted r.m.s. acceleration may be likely to be.

3) It is clear that the heavier the body weight of each operator, the smaller frequency-weighted r.m.s. acceleration is likely to be.

4) It follows that the stronger the grip of each operator, the smaller frequency-weighted r.m.s. acceleration seems to be.

5) It is found that the bigger the BMI of each operator, the smaller frequency-weighted r.m.s. acceleration is likely to be.

To sum up, insofar as the vibrating acceleration of the tool is measured with an operator, the same results as those of this study is deemed to be obtained according to the physical characteristics of an operator. Hence, it seems to be necessary that the provision on an operator should be made by means of such figures as his or her BMI, not with the ambiguous expression of "skilled operators", and further consideration on the way an operator is selected ought to be made in detail.

\section{References}

1) ISO8662-7:1997 Hand-held portable power toolsMeasurement of vibrations at the handle-Part 7:
Wrenches, screwdrivers and nut runners with impact, impulse or ratchet action.

2) ISO5349:1986 Mechanical vibration-Guidelines for the measurement and the assessment of human exposure to hand-transmitted vibration.

3) Council Directives, "On the approximation of the laws of the Member States relating to machinery," Off. J. Eur. Committies No. L183, 9-26 (1989).

4) ISO8662-1:1988 Hand-held portable power toolsMeasurement of vibrations at the handle-Part 1 . General.

ISO8662-2:1992 (Ditto)_Part2. Chipping hammers and riveting hammers.

ISO8662-3:1992 (Ditto)—Part3. Rock drills and rotary hammers.

ISO8662-4:1994 (Ditto)_Part4. Grinders.

ISO8662-5:1992 (Ditto)_Part5. Pavement breakers and hammers for construction work.

ISO8662-6:1994 (Ditto)_Part6. Impact drills.

ISO8662-7:1997. Ref. to No. 1

ISO8662-8:1997 (Ditto)-Part8.Polishers and rotary, orbital and random orbital sanders.

ISO8662-9:1996 (Ditto)_Part9. Rammers.

ISO8662-10:1998 (Ditto)_Part10. Nibblers and shears. ISO8662-11:1999 (Ditto)_Part11. Fastener driving tools.

ISO8662-12:1997 (Ditto)_Part12. Saws and files with reciprocating action and saws with oscillating or rotating action.

ISO8662-13:1997 (Ditto)_Part13. Die grinders. ISO8662-14:1996(Ditto)_Part14. Stone-working tools and needle scalers.

5) ISO2787:1984 Rotary and percussive pneumatic toolsPerformance tests.

6) University of Southampton, HVLab Data Acquisition and Analysis System, Version 3.81, 1999. 